\title{
Geophysical Indicators of Gas Hydrate in the Northern Continental Margin, South China Sea
}

\author{
Xiujuan Wang, ${ }^{1,2}$ Shiguo Wu, ${ }^{1}$ Yiqun Guo, ${ }^{3}$ Shengxiong Yang, ${ }^{3}$ and Yuehua Gong ${ }^{3}$ \\ ${ }^{1}$ Institute of Oceanology, Chinese Academy of Sciences, Qingdao 266071, China \\ ${ }^{2}$ Key Laboratory of Marine Hydrocarbon Resources and Environmental Geology, Ministry of Land and Resources, \\ Qingdao 266071, China \\ ${ }^{3}$ Guangzhou Marine Geological Survey, MLR, Guangzhou 510760, China \\ Correspondence should be addressed to Xiujuan Wang, wangxiujuan@qdio.ac.cn \\ Received 7 April 2011; Revised 11 August 2011; Accepted 11 August 2011 \\ Academic Editor: Umberta Tinivella
}

Copyright ( $) 2011$ Xiujuan Wang et al. This is an open access article distributed under the Creative Commons Attribution License, which permits unrestricted use, distribution, and reproduction in any medium, provided the original work is properly cited.

Gas hydrate drilling results show that gas hydrate has a close relationship with strong bottom-simulating reflectors (BSRs) identified from seismic data in the Baiyun sag, South China Sea. The BSRs observed on seismic profiles at the crests of submarine canyons indicate the likely existence of gas hydrate. We calculate the acoustic impedance using constrained sparse spike inversion (CSSI), the interval velocity, and the seismic reflection characteristics such as reflection strength, instantaneous frequency, blanking, and enhanced reflection to demonstrate the presence of gas hydrate. Higher acoustic impedance and P-wave velocity were identified above the BSR. A remarkable low impedance, low frequency, and acoustic blanking indicated the presence of gas below gas hydrate stability zone. The occurrence of gas hydrate at the crests of canyons suggests that the abundance of gas hydrate in Baiyun sag may be due to the migrating submarine canyons providing the structural reliefs and the topographic ridges.

\section{Introduction}

Gas hydrates are ice-like crystalline solids and are composed of water molecules and hydrocarbon gas (usually methane). They are distributed worldwide in the continental margin sediments and beneath permafrost $[1,2]$. Bottom simulating reflectors (BSRs) identified from seismic reflection profiles are conventionally interpreted as indicators for gas hydrate beneath seafloor [3]. Gas hydrates-associated BSRs have been recognized from the seismic data of other geophysical studies, and their presences have been validated by drilling or coring either in accretionary wedges [4-7] or in the continental margin of the world [8-11]. The Hikurangi Margin, east of New Zealand's North Island, is a large marine gas hydrate province. The BSRs were identified on the multichannel seismic data and there is a strong correlation between BSR strength and geological features indicating the fluid migration $[12,13]$. Geophysical parameters show that gas hydrate-bearing sediments have high elastic impedance, high P-impedance, and high P-wave velocity; and the sediments containing free gas have low elastic impedance, low $\mathrm{P}$-impedance, and low $\mathrm{P}$-wave velocity [14]. The anomalous velocity and the variation in amplitude and polarity of reflectors at the base of gas hydrate-bearing stability zone were used to indicate the presence of gas hydrate $[15,16]$. The acoustic impedance inversion of seismic data, log to seismic correlation, and seismic attribute analyses were combined to delineate gas hydrate zone [17].

In China, eight sites were drilled in 2007 in Shenhu area, Pearl River Mouth basin (PRMB), the northern slope of South China Sea [18]. Gas hydrate samples were recovered from pressure cores at sites $\mathrm{SH} 2, \mathrm{SH} 3$, and $\mathrm{SH} 7$ in silt and silty-clay sediments with a maximum value of $47 \%$ of pore space. High-resolution multichannel 2D and 3D seismic surveys have been carried out for gas hydrate resource studies in the northern SCS. BSRs have been identified in the Xisha Trough [19], Qiongdongnan (QDN) Basin [11], in Pearl River Mouth basin (PRMB) [20] and in the Taixinan Basin of the northern SCS $[21,22]$. In the PRM basin, modern submarine canyons have been identified, which are sublinear, subparallel, regularly-spaced extending from the shelf-break at $450 \mathrm{~m}$ water depth to their terminations at $1500 \mathrm{~m}$ water depth on the north flank [23]. These canyons have lengths of $30-60 \mathrm{~km}$ and have widths of $1-5.7 \mathrm{~km}$, while the relief 
ranges from 50 to $300 \mathrm{~m}$. Gas hydrates have been drilled in higher relief of the ridges in one of the canyons in 2007. Highamplitude anomalies or bright spots have been observed in the Miocene sequences on the seismic profiles in the deep-water areas [24]. Faults and gas chimneys acted as pathways for upward migration of gas from source rocks to the shallower sediments [25].

The main objective of this study is to use the Pimpedance profile obtained from Constrained Sparse Spike Inversion (CSSI) and geophysical attributes computed from 3D seismic data to show the presence of gas hydrate.

\section{Geological Setting}

The SCS is the largest marginal sea in the western Pacific and covers an area of $3.5 \times 10^{6} \mathrm{~km}^{2}$ [27]. PRMB and QDN basins located on the northern slope of SCS are Cenozoic rift basins developed on Mesozoic basement, and gas hydrates have been drilled in this basin (Figure 1). The structural evolution of basins can be divided into two stages: an Eocene-Oligocene rift and a Neogene-Quarternary postrift thermal subsidence [24]. In response to the structural evolution, the sedimentary deposition environment changed from paleolakes in the early stage to an open-marine setting in the late stage. The Wenchang and Enping formations in this basin are the source rocks of the Eocene rift stage with a total thickness of $3000 \mathrm{~m}$. During the postrifting stage, the SCS entered into a period of subsidence. The thickness of marine facies in this stage came up to $6000 \mathrm{~m}$ because Baiyun sag located at the downdip direction of paleo-Pearl River and the sea level decreased. In the QDN basin, the Yacheng Formation was deposited during the early Oligocene consisting mainly of neritic mudstones and coastal plain coal-bearing strata which was the main hydrocarbon source rock in this basin [25].

The SCS has the favorable temperature and pressure condition for the formation of gas hydrate. The water depth ranges from 150 to $3700 \mathrm{~m}$. The QDN basin is characterized by the geothermal gradients with the values of $39-41^{\circ} \mathrm{C} / \mathrm{km}$ and high sedimentation rates (up to $1.2 \mathrm{~mm} / \mathrm{yr}$ ). The average geothermal gradient in the PRM basin is about $36^{\circ} \mathrm{C} / \mathrm{km}$. However, it goes up to $67.7^{\circ} \mathrm{C} / \mathrm{km}$ in the gas hydrate drilling zone from the in situ temperature measurement [26].

\section{Seismic Data and Methods}

3.1. Data. The seismic line A and line C were collected in 2006 with the following a 3000-m long streamer with 240 channels (trace interval $12.5 \mathrm{~m}$ ) and a tuned airgun source with a total volume of $8 \times 20$ inch $^{3}$ shooting every $25 \mathrm{~m}$. The seismic processing sequences mainly include prefiltering, true amplitude recovery, noise attenuation, deconvolution, velocity analysis (first), residual statics, velocity analysis (second), multiple attenuation, DMO velocity analysis, DMO stack, and noise attenuation. The seismic line B is one of the $3 \mathrm{D}$ seismic data with the same location of seismic line A. The seismic data were acquired by the single-source and single-streamer method using the influence of ocean current on the cable so that the dense $2 \mathrm{D}$ seismic data can form one overlap. As the azimuth angle is narrow and the aim layer is shallow, the processing method is quite different from the traditional 3D seismic processing. The true amplitude, noise attenuation, and deconvolution were used to emphasize the characterization of gas hydrate. The data were processed with a bin spacing in the in-line and cross-line directions of $12.5 \mathrm{~m}$ and $25 \mathrm{~m}$, respectively [28].

3.2. Constrained Sparse Spike Inversion (CSSI). Acoustic impedance is obtained from the product of density and seismic velocity, so it can be defined as a layer property and not as an interface property. The acoustic impedance can be directly related to porosity, lithology, and permeability. Although seismic data can be interpreted on its own without inversion, but this does not provide the most detailed view of the subsurface and can be misleading under certain conditions.

Seismic inversion has been used for several decades in the petroleum industry. Seismic inversion methods have progressed from the initial recursive inversion to present software package available to transform band-limited seismic traces to impedance traces. Stochastic seismic inversion combined the seismic and log data to derive the vertical resolution from the log data [29]. Constrained sparse spike inversion (CSSI) is based on seismic data and low-frequency impedance information obtained from well data. Although strictly speaking this technique does not depend on well data, the precision of the results does depend somewhat on the number of wells used. The inversion of seismic data to obtain acoustic impedance for the Baiyun sag was performed with the CSSI package of Jason Geosystems, which involves the following stages.

(1) Wavelet is estimated by using seismic and pseudowell data at the arbitrary CMP. We first create the Ricker wavelet and then we make synthetic seismogram at different locations. The input wavelet was the scaled average wavelet based on different wells. (2) The low-frequency information is constructed by using the EarthModel model generator. The trace gate, solid model created using the interpreted horizons and structural information, and the interpolation method of natural neighbour were chosen to generate the low frequency impedance data. (3) The bandpass P-impedance data are obtained by choosing the sparse spike parameters such as weighting factor in the inversion process. (4) Last, the lowfrequency model is merged with the band pass $\mathrm{P}$-impedance.

CSSI determines the acoustic impedance within prescribed constraints by minimizing the objective function

$$
F_{\text {obj }}=\sum\left(r_{i}\right)^{p}+\lambda^{q} \sum\left(d_{i}-s_{i}\right)^{q}
$$

at time $i$, where $r_{i}$ is the reflection coefficient, $d_{i}$ the recorded seismic trace, $s_{i}$ the synthetic trace, $p$ and $q$ empirically determined exponents, and $\lambda$ the data mismatch weighting factor. The match between output impedance and seismic data is determined by $\lambda$. If $\lambda$ is lower than the "true" value, then the match between the synthetic trace and the recorded seismic data worsens and the output impedance is very approximate. As $\lambda$ approaches its "true" value, the match improves and the output impedance provides a better 


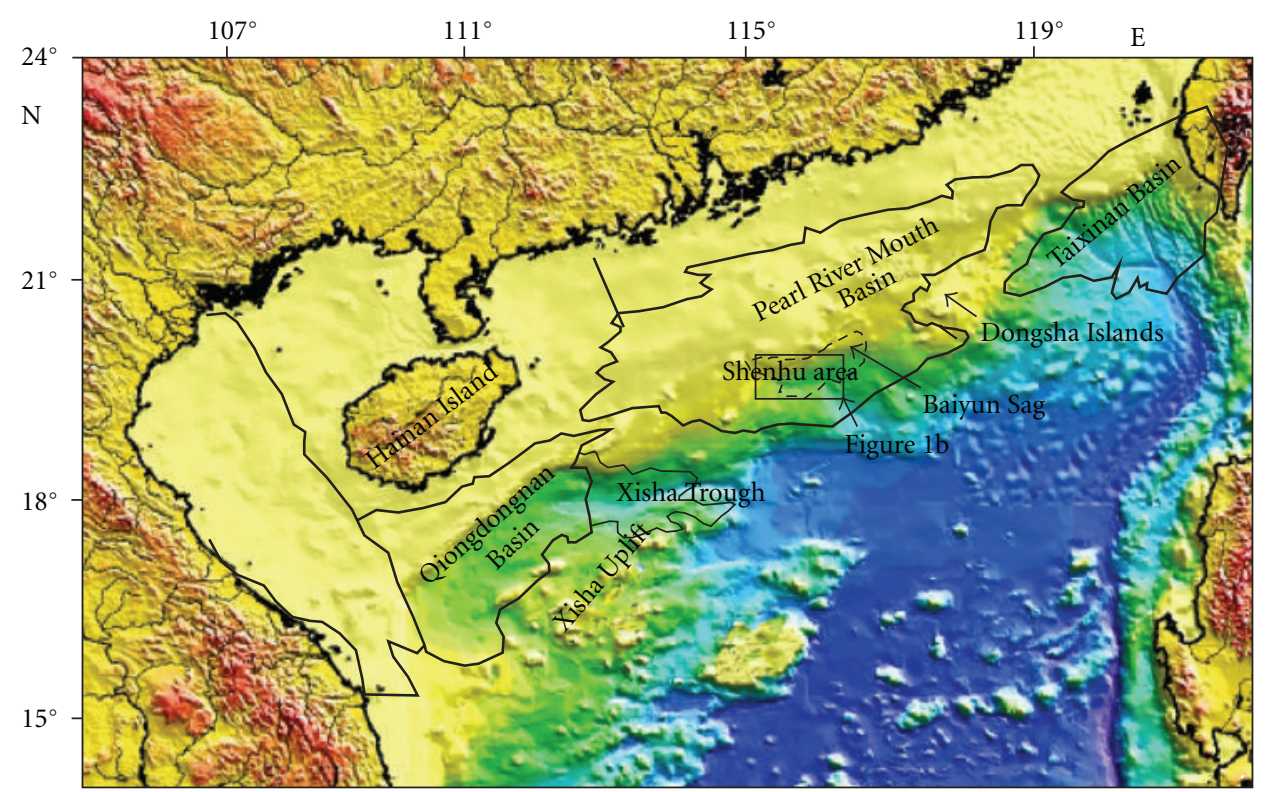

(a)

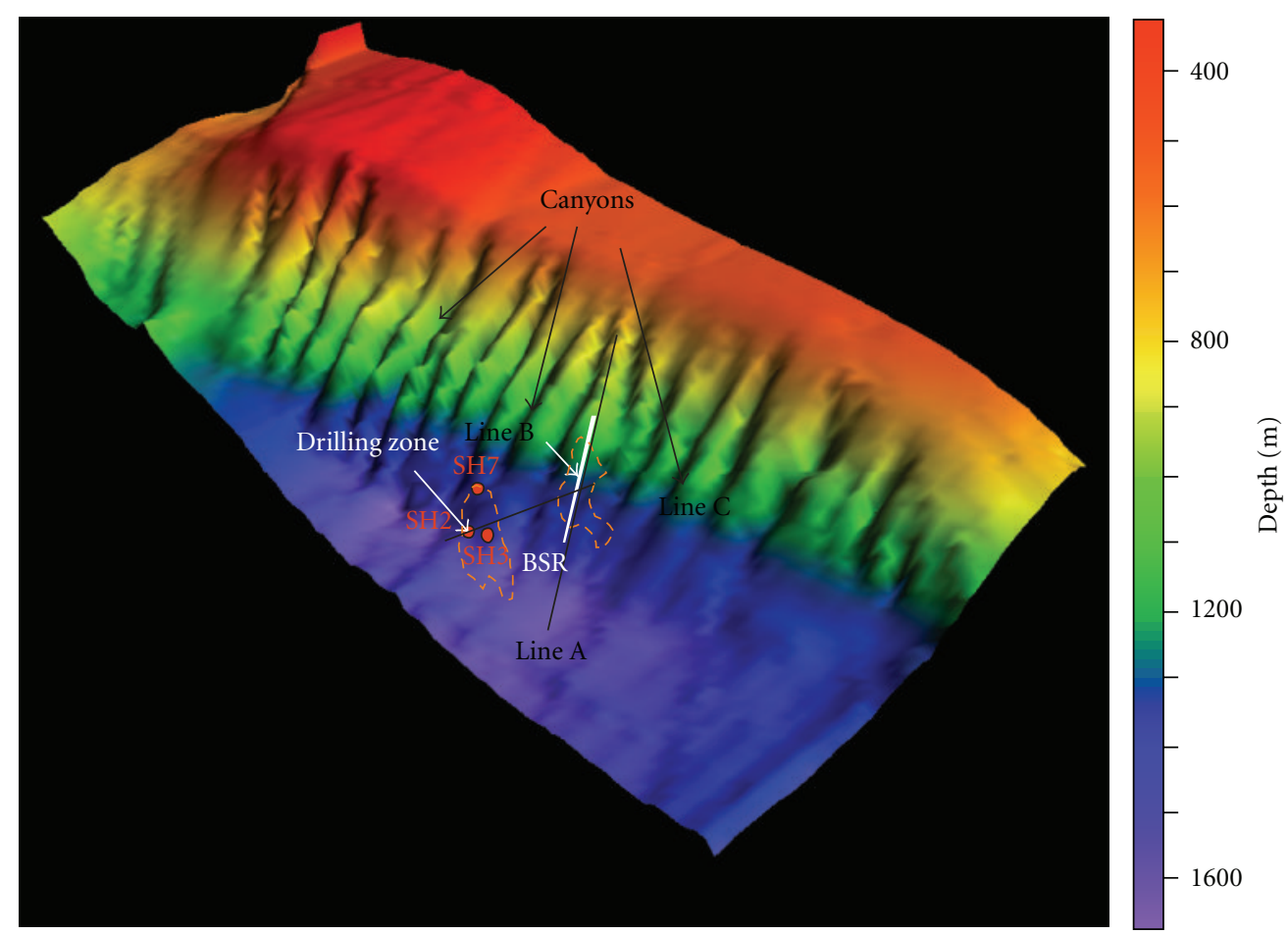

(b)

Figure 1: (a) Areas of gas hydrate exploration in the northern part of the South China Sea and the gas hydrate drilling zone of Shenhu area, Baiyun sag; (b) Bathymetric map of Baiyun sage that was interpolated by the 2D seismic data in this area. Modern canyons shown by Zhu et al. [23] were also identified. Black lines and white line show seismic line A, line B, and line C used in the paper. The zones surrounded by broken yellow lines show the BSR on the seismic lines and in the gas hydrate drilling zone in 2007 [26].

description of the physical properties of the sediment. The factors $p$ (reflectivity norm) and $q$ (seismic mismatch norm) are 1 and 2 by default, respectively. The value of $\lambda$ is optimized for signal-to-noise, correlation misfit, seismic misfit, and reflectivity misfit. For the inversion of seismic line, we used $\lambda=13, p=1$, and $q=2$.
3.3. Seismic Attributes. Seismic attributes like instantaneous frequency, instantaneous phase, blanking, and reflection strength have been used to identify gas hydrate from seismic data [30-32].

The Variance Cube operation was used to highlight faults and subtle stratigraphic features in a $3 \mathrm{D}$ seismic volume. 


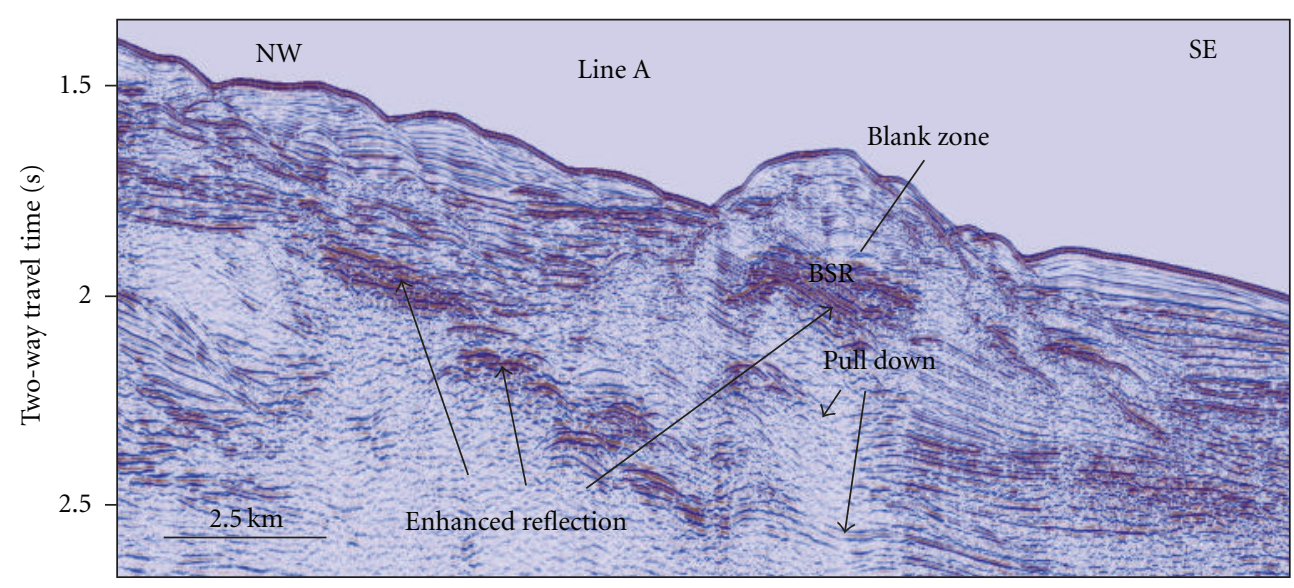

(a)

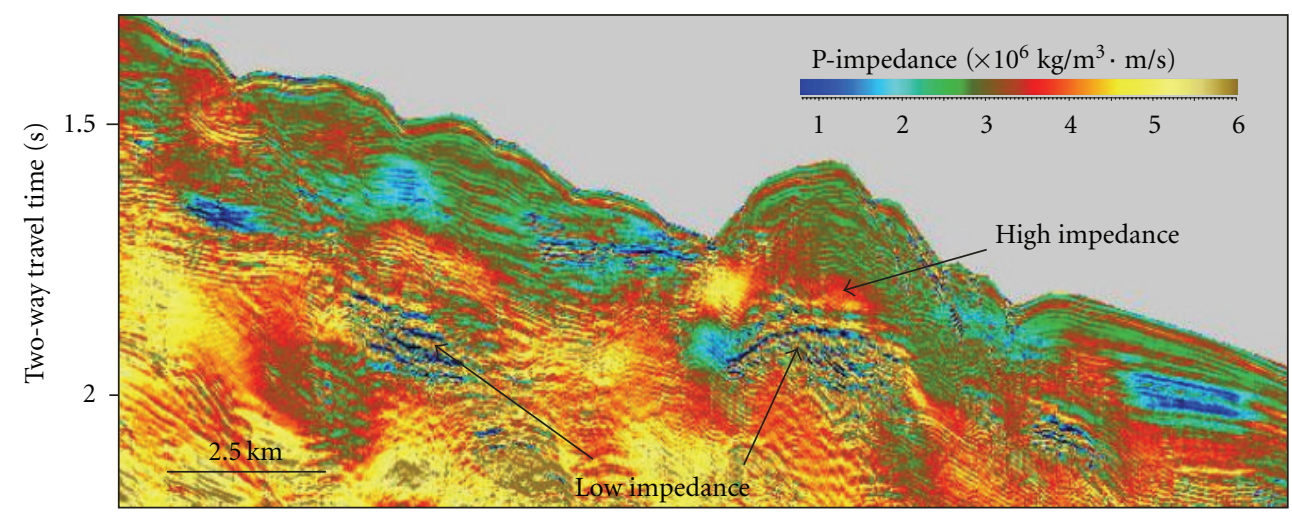

(b)

FIGURE 2: In Baiyun sag. (a) The variable-density display of part profile of seismic line A; A strong bottom-simulating reflector and enhanced reflections can be easily identified. (b) The acoustic impedance estimation obtained by CSSI. High acoustic impedance above the BSR is present and low impedance is shown below the BSR.

In the output cube, incoherent (high amplitude) areas are displayed in high contrast (black). In the Seis 3DV, the output variance cube can be shown the inline or crossline profile and compared it with the seismic profile. As the 3D seismic data is pseudo-3D seismic data, we calculated the coherence in larger window length and we compare it with the seismic profile. The output values vary between 0 indicating the worst, and 1 indicating the best.

The instantaneous frequency is a time or depth derivative of the instantaneous phase and a measure of the frequency of the waveform at every sample. It is independent of reflection magnitude, weak events, and noise, which are all equally weighted in display. The minimum and maximum frequencies can be given in the output. The instantaneous frequency attribute is considered a good tool for lateral seismic character correlation. Oil and gas may preferentially attenuate higher frequencies so a low instantaneous frequency anomaly has been used to predict conventional hydrocarbons accumulations in the oil industry.

The reflection strength is simply an expression of the amplitude envelope of the seismic trace and is independent of phase. It shows the total energy of the seismic signal and has the maximum value at point other than the peak or trough of the real trace, especially when the event is the composite of several reflections [28]. The reflection strength depends on the contrast of acoustic impedance. The strong reflection indicates the apparent changes in the seismic impedance contrast.

\section{Results}

4.1. Geophysical Attributes. One reflector is located at about $280 \mathrm{~ms}$ of two-way travel time below seafloor, which has the reversed polarity compared with the seafloor in seismic line A (Figure 2). Blanking is the reduction of amplitude of the seismic reflection, which appears to be caused by the presence of gas hydrate. Amplitude blanking is identified above this reflector. On the upper slope within the Baiyun sag, this reflector and associated amplitude anomalies are relatively indistinct comparing to the ridge crest. Enhanced reflections are identified in the shallow sediments. Below this reflector of the crest, the down-warped reflectivity may be related to the presence of focused or concentrated gas. This anomaly is interpreted as a reduction of the seismic velocity (pull-down effect) through a gas-charged column. The acoustic impedances above this reflector range from 


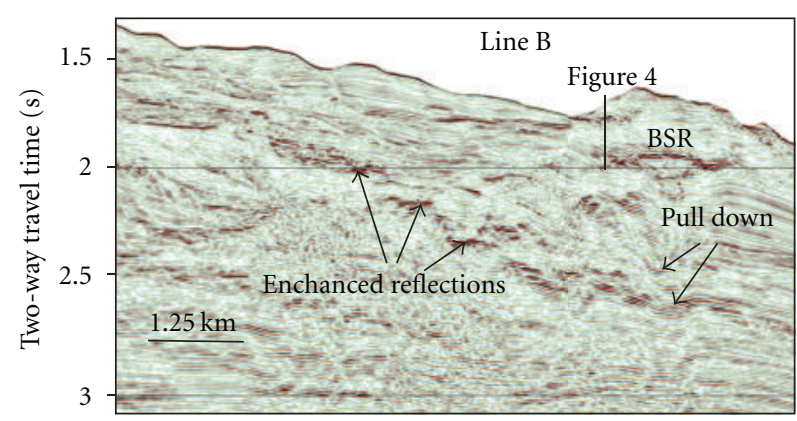

(a)

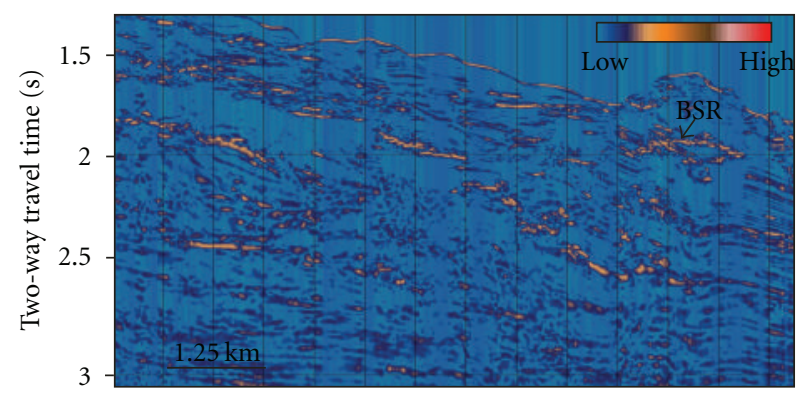

(c)

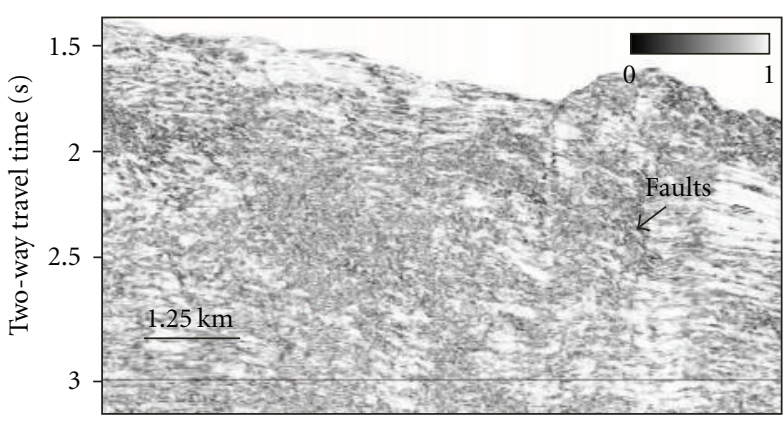

(b)

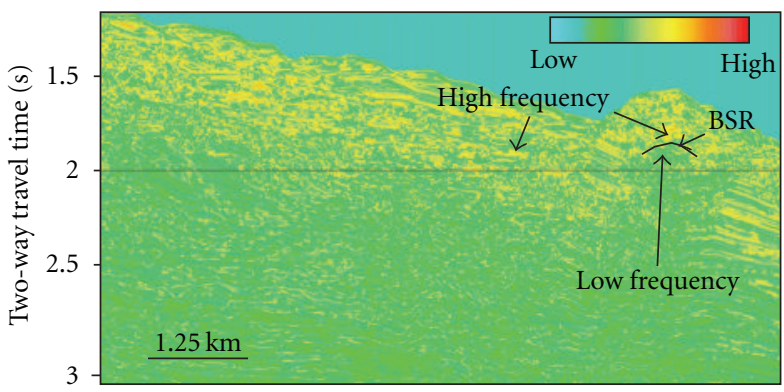

(d)

FIgURE 3: (a) Part of seismic line B that is parallel to seismic line A, which can show the continuous reflections of the sediments. Enhanced reflections are identified at the similar locations to seismic line A; (b) Coherence profile for the seismic line B showing the faults and subtle stratigraphic change. (c) Reflection strength profile for the line, showing loss of amplitude above the BSR and the enhanced reflection. (d) Instantaneous frequency profile shows high frequency above the interpreted BSR caused by the presence of gas hydrate and low frequency zone below the interpreted BSR caused by the presence of free gas.

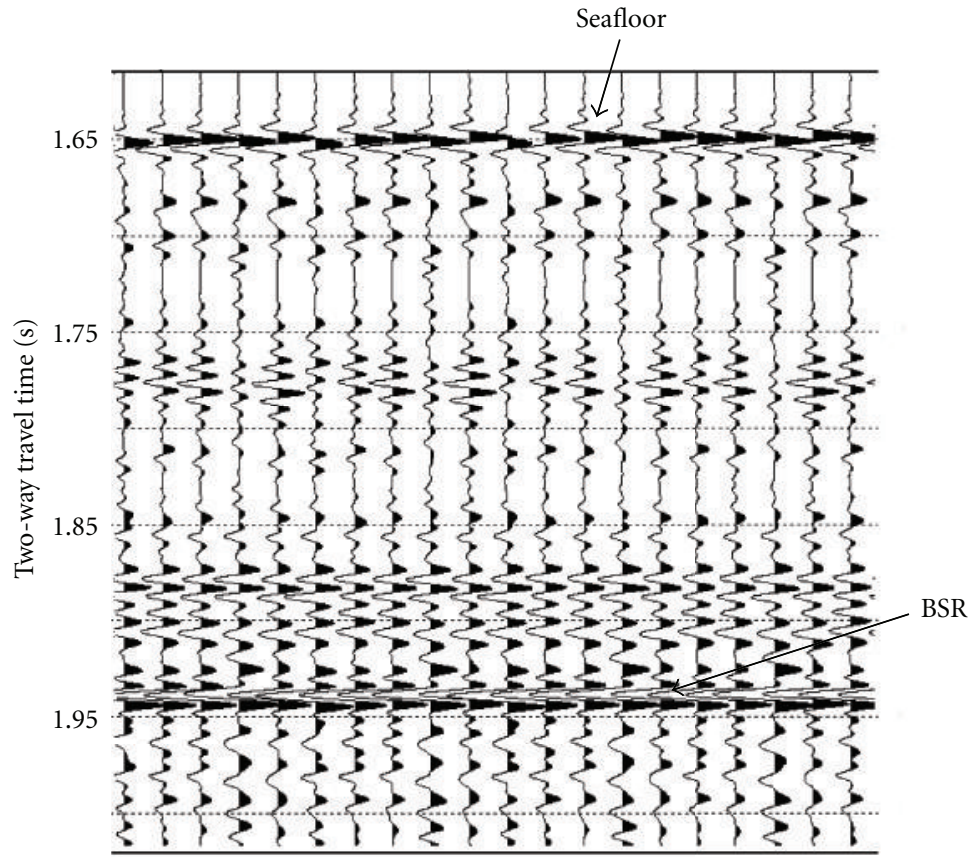

(a)

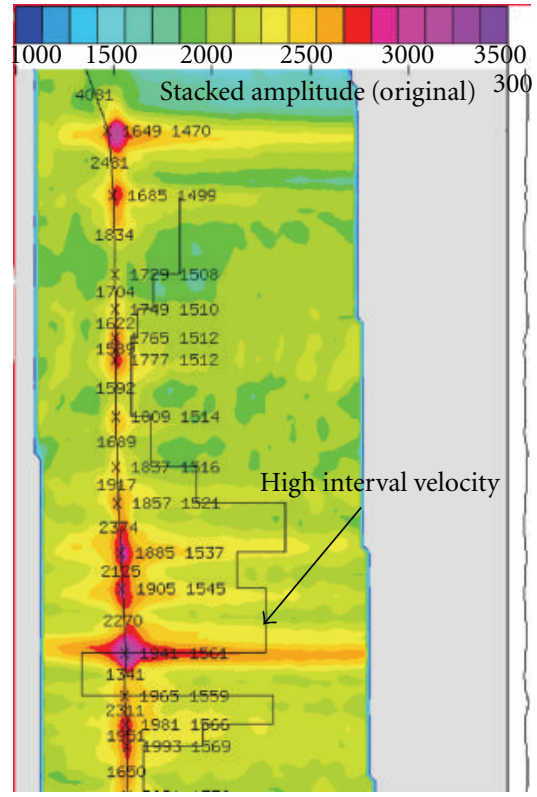

(b)

FIgURE 4: CMP gather shows how interval velocities were obtained. (a) Normal-moveout-corrected CMP gather shown in Figure 3(a). (b) shows the semblance plot and the interval velocity calculated from the Dix equation for the crosses locations. Higher interval velocity is shown in the layer of $1.85-1.95 \mathrm{~s}$. 


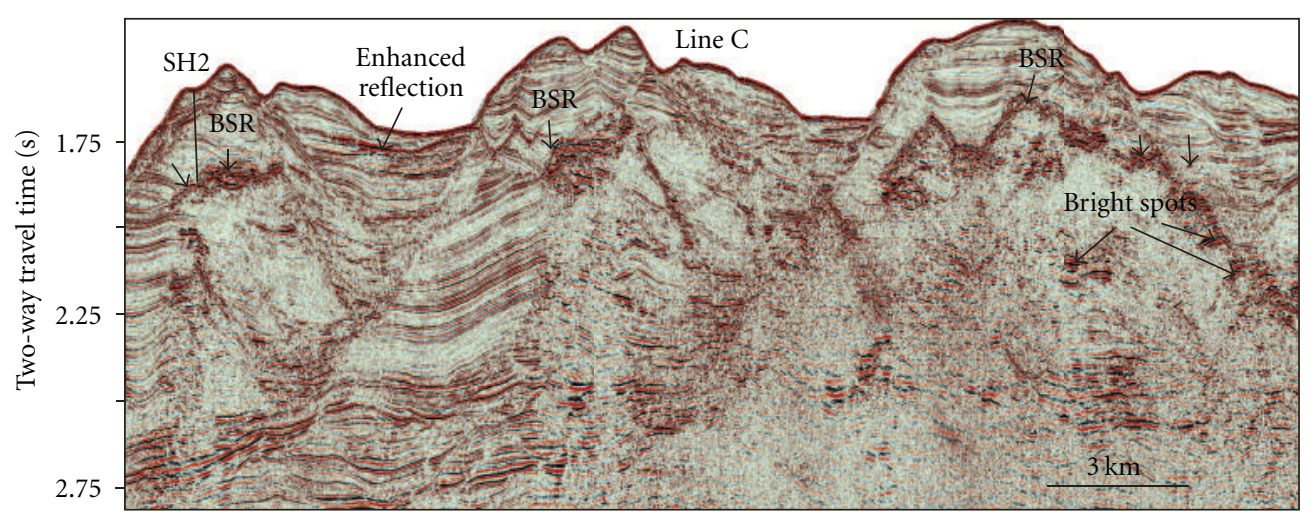

(a)

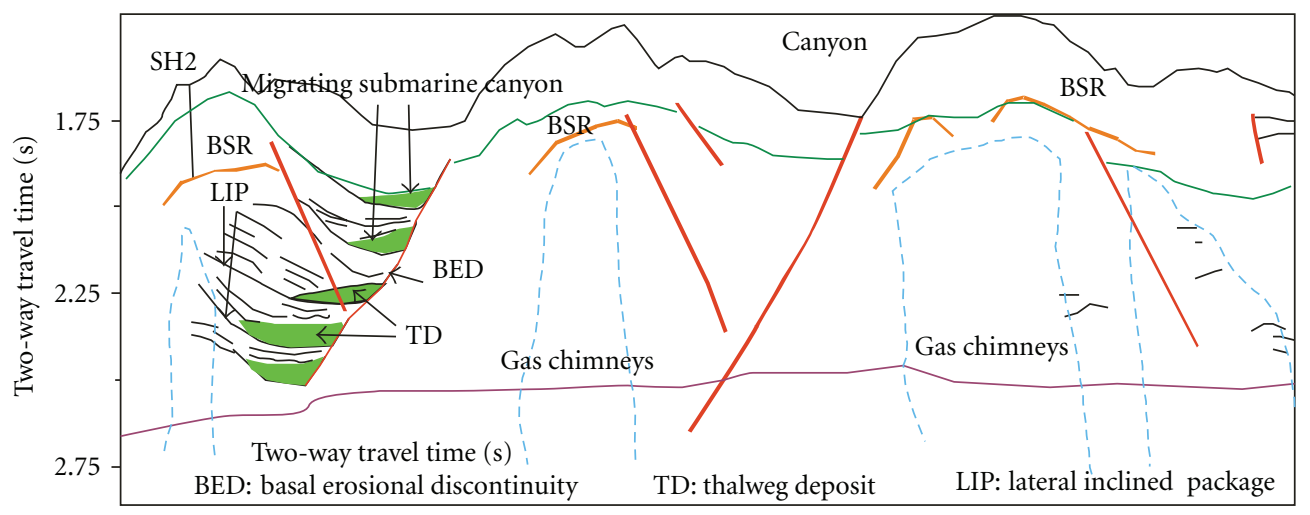

(b)

FIGURE 5: Part of seismic line C profile (a) and interpreted profile showing BSR, gas chimneys, and migrating submarine canyons, Baiyun Sag, Pearl River Mouth Basin, South China Sea (b).

$3.5 \times 10^{6}$ to $4.5 \times 10^{6} \mathrm{~kg} / \mathrm{m}^{3} \cdot \mathrm{m} / \mathrm{s}$, which have higher impedances than the sediments of water-saturated zone indicating the presence of gas hydrate above this reflector. Below it, lower impedance indicates the presence of free gas.

Seismic line $\mathrm{B}$ is one of the inline of $3 \mathrm{D}$ seismic data which is parallel to seismic line A (Figure 1). We put them together to obtain more seismic attributes and to show the evidence of gas hydrate in this region from seismic profile. The reflector of seismic line $\mathrm{B}$ is more continuous than that of seismic line A. Seismic line B shows the reflectors clearly in the several zone where they are wipe-out reflection or lower amplitude in seismic line A. However, the pulldown effect and enhanced reflection below the reflector of reversed polarity to seafloor are more prominent in the seismic line B profile (Figure 3(a)). The coherence profile can show the faults and the chaotic reflection below the bright spots (Figure 3(b)). Figure 3(c) shows the reflection strength for the seismic line B. Blue and red show the amplitude anomalies with low and high amplitudes, respectively. The blanking zone in the seismic profile and the coherence is better, which may be caused by the cementation of gas hydrate. The instantaneous frequency profile in Figure 3(d) shows the high frequencies in red and the low frequencies in green. The lower instantaneous frequency may be caused by the presence of free gas. The frequency indicates that the attenuation in free gas-bearing sediment is higher than that of gas hydrate-bearing sediments.

4.2. P-Wave Velocity. Geophysical attributes show an indictor of the presence of gas hydrate in seismic lines A and B. The direct indicator of gas hydrate is the study of the anomalies in the P-wave velocity above and below BSR. Higher velocities should be associated with gas hydrate and lower velocities should be associated with free gas. Figure 4 shows the CMP gather in Figure 3(a) location. It shows numerous clear reflections and semblance peaks. The stacking velocity picks were made at the locations where the semblances are high. The interval velocities show anomalously high at 1.85$1.95 \mathrm{~s}$, which range from 1850 to $1900 \mathrm{~m} / \mathrm{s}$ (Figure 4 ). The high interval velocity above the strong reflector of the crest indicates a gas hydrate-bearing zone near the drilling area in 2007.

4.3. Seismic Facies of Canyons. Seismic line C passed through site $\mathrm{SH} 2$ (Figure 5). BSRs identified in the Baiyun sag are stronger at the ridges of submarine canyons than those of the canyons axes. Seismic profile shows that canyon walls abruptly terminate surrounding sub-parallel-bedded, inclined reflections which are interpreted as progradational deposits. 
The submarine canyon near site $\mathrm{SH} 2$ was interpreted to show the migration of the canyon. It has been referred that the thalwegs of the submarine canyons are progressively offset toward the northeast from the middle Miocene to present [23], which also was identified in Figure 5. Each cycle of the canyon is marked by a basal erosional discontinuity (BED) at the base. The thalweg deposits (TD) are overlain by a lateral inclined package (LIP) and are marked by lens-shaped, parallel, high amplitude, continuous reflections that onlap basal erosional discontinuities. Canyon margin deposits consist of continuous reflections with high amplitude, and truncated by basal erosional discontinuities. Gas chimneys are identified below crests of submarine canyons and are characterized vertical disturbances in seismic data and low seismic amplitudes, which are interpreted to be associated with the upward migration of free gas (Figure 5). Gas chimneys and the erosion of migrating submarine canyons acted as major pathways for gas migration. Bright spots shown below the base of gas hydrate stability (BGHS) indicate that the occurrence of gas hydrate decrease the permeability of the sediments. Gas was trapped below the gas hydrate stability zone, which has been identified from the low acoustic impedance in seismic line A (Figure 2(b)).

\section{Conclusion}

Gas hydrates have been identified by the gas hydrate drilling exploration at the Shenhu area, Baiyun sag, Pearl River Mouth basin, South China Sea. Another gas hydrate province was identified at the adjacent canyon by using new seismic data and seismic attributes. Amplitude blanking, high acoustic impedance, high frequency and enhanced reflections identified from the $2 \mathrm{D}$ and $3 \mathrm{D}$ seismic profiles at about $280 \mathrm{~ms}$ of two-way travel time below seafloor were caused by the presence of gas hydrate. The reflector that is subparallel to the seafloor and cuts across the strata is the BSR. The acoustic impedance profile has lower impedance below it. A strong reflection at the BSR was observed in the reflection strength profile, and low frequencies were seen below the BSR from the instantaneous frequency profile. These anomalies suggest the presence of free gas below the BSR. The distribution of BSRs has a close relationship with the submarine canyons and gas chimneys. Prominent and strong BSRs exist in the crests of the migrating submarine canyons in the middle of Baiyun sag. Few BSRs are found in the axes of these canyons, which are controlled by the geological setting in this basin.

\section{Acknowledgments}

The authors would like to thank the team of Guangzhou Marine Geological Survey for shooting the seismic data used in this paper. Our research is supported by the International Science and Technology Cooperation Program of China (2010DFA21740), National Basic Research Program (2009CB219505), and Key Laboratory of Marine Hydrocarbon Resources and Environmental Geology, Ministry of Land and Resources (MRE201105).

\section{References}

[1] K. A. Kvenvolden and T. D. Lorenson, "The global occurrence of natural gas hydrates," in Natural Gas Hydrates: Occurrence, Distribution and Detection, C. K. Paull and W. P. Dillon, Eds., Geophys Monogr Ser, 124, pp. 3-18, AGU, Washington, DC, USA, 2001.

[2] B. A. Buffett, "Clathrate hydrates," Annual Review of Earth and Planetary Sciences, vol. 28, pp. 477-507, 2000.

[3] W. P. Dillon and C. Paull, "Marine gas hydrates, II-Geophysical evidence," in Natural Gas Hydrates: Properties, Occurrences and Recovery, J. L. Cox, Ed., pp. 73-90, Butter Worths, 1983.

[4] M. Riedel, T. Collett, and M. Malone, "Expedition 311scientists," in Proceedings of the Integrated Ocean Drilling Program, 311, Ocean Drilling Program, Washington, DC, USA, 2006.

[5] J. Ashi, H. Tokuyama, and A. Taira, "Distribution of methane hydrate BSRs and its implication for the prism growth in the Nankai Trough," Marine Geology, vol. 187, no. 1-2, pp. 177191, 2002.

[6] C. C. Lin, A. T.-S. Lin, C. S. Liu, G. Y. Chen, W. Z. Liao, and P. Schnurle, "Geological controls on BSR occurrences in the incipient arc-continent collision zone off southwest Taiwan," Marine and Petroleum Geology, vol. 26, no. 7, pp. 1118-1131, 2009.

[7] A. M. Tréhu, P. E. Long, M. E. Torres et al., "Threedimensional distribution of gas hydrate beneath southern Hydrate Ridge: constraints from ODP Leg 204," Earth and Planetary Science Letters, vol. 222, no. 3-4, pp. 845-862, 2004.

[8] W. S. Holbrook, H. Hoskins, W. T. Wood, R. A. Stephen, and D. Lizarralde, "Methane hydrate and free gas on the Blake Ridge from vertical seismic profiling," Science, vol. 273, no. 5283, pp. 1840-1843, 1996.

[9] T. S. Collett, C. C. Knapp, A. H. Johnson, and R. Boswell, "Natural gas hydrate: a review," AAPG Memoir, vol. 89, pp. 146-219, 2009.

[10] X. Wang, S. Wu, S. Yuan et al., "Geophysical signatures associated with fluid flow and gas hydrate occurrence in a tectonically quiescent sequence, Qiongdongnan Basin, South China Sea," Geofluids, vol. 10, no. 3, pp. 351-368, 2010.

[11] K. Sain and H. Gupta, "Gas-hydrates: Indian scenario," Journal of the Geological Society of India, vol. 72, no. 3, pp. 299-311, 2008.

[12] I. A. Pecher, S. A. Henrys, W. T. Wood et al., "Focussed fluid flow on the Hikurangi Margin, New Zealand-evidence from possible local upwarping of the base of gas hydrate stability," Marine Geology, vol. 272, no. 1-4, pp. 99-113, 2010.

[13] G. J. Crutchley, A. R. Gorman, I. A. Pecher, S. Toulmin, and S. A. Henrys, "Geological controls on focused fluid flow through the gas hydrate stability zone on the southern Hikurangi Margin of New Zealand, evidenced from multichannel seismic data," Marine and Petroleum Geology. In press.

[14] S. Lu and G. A. McMechan, "Elastic impedance inversion of multichannel seismic data from unconsolidated sediments containing gas hydrate and free gas," Geophysics, vol. 69, no. 1, pp. 164-179, 2004.

[15] G. K. Westbrook, S. Chand, G. Rossi et al., "Estimation of gas hydrate concentration from multi-component seismic data at sites on the continental margins of NW Svalbard and the Storegga region of Norway," Marine and Petroleum Geology, vol. 25, no. 8, pp. 744-758, 2008.

[16] J. M. Carcione, D. Gei, G. Rossi, and G. Madrussani, "Estimation of gas-hydrate concentration and free-gas saturation 
at the Norwegian-Svalbard continental margin," Geophysical Prospecting, vol. 53, no. 6, pp. 803-810, 2005.

[17] M. Riedel, G. Bellefleur, S. Mair, T. A. Brent, and S. R. Dallimore, "Acoustic impedance inversion and seismic reflection continuity analysis for delineating gas hydrate resources near the Mallik research sites, Mackenzie Delta, Northwest Territories, Canada," Geophysics, vol. 74, no. 5, pp. B125-B137, 2009.

[18] H. Q. Zhang, S. X. Yang, N. Y. Wu et al., "Successful and surprising results for China's first gas hydrate drilling expedition. Fire in the Ice," Methane Hydrate Newsletter, National Energy Technology Laboratory, US Department of Energy, Fall issue 6-9, 2007.

[19] S. Wu, G. Zhang, Y. Huang, J. Liang, and H. K. Wong, "Gas hydrate occurrence on the continental slope of the northern South China Sea," Marine and Petroleum Geology, vol. 22, no. 3, pp. 403-412, 2005.

[20] T. M. Guo, B. H. Wu, Y. H. Zhu, S. S. Fan, and G. J. Chen, "A review on the gas hydrate research in China," Journal of Petroleum Science and Engineering, vol. 41, no. 1-3, pp. 11-20, 2004.

[21] S. Wu, X. Wang, H. K. Wong, and G. Zhang, "Low-amplitude BSRs and gas hydrate concentration on the northern margin of the South China Sea," Marine Geophysical Researches, vol. 28, no. 2, pp. 127-138, 2007.

[22] G. X. Zhang, Y. Y. Huang, Y. H. Zhu, and B. H. Wu, "Prospect of gas hydrate resources in the South China Sea," Marine Geology and Quaternary Geology, vol. 22, no. 1, pp. 75-81, 2002 (Chinese).

[23] M. Zhu, S. Graham, X. Pang, and T. McHargue, "Characteristics of migrating submarine canyons from the middle Miocene to present: Implications for paleoceanographic circulation, northern South China Sea," Marine and Petroleum Geology, vol. 27, no. 1, pp. 307-319, 2010.

[24] K. Ru and J. D. Pigott, "Episodic rifting and subsidence in the South China Sea," AAPG Bulletin, vol. 70, pp. 1136-1155, 1986.

[25] W. Zhu, B. Huang, L. Mi, R. W. T. Wilkins, N. Fu, and X. Xiao, "Geochemistry, origin, and deep-water exploration potential of natural gases in the Pearl River Mouth and Qiongdongnan Basins, South China sea," AAPG Bulletin, vol. 93, no. 6, pp. 741-761, 2009.

[26] N. Y. Wu, S. X. Yang, H. Q. Zhang, J. Q. Liang, H. B. Wang, and J. A. Lu, "Gas hydrate system of Shenhu area, northern South China Sea: wire-line logging, geochemistrical results and preliminary resources estimates," OCT 20485, pp. 1-13, 2010.

[27] M. J. Higginson, J. R. Maxwell, and M. A. Altabet, "Nitrogen isotope and chlorin paleoproductivity records from the Northern South China Sea: remote vs. local forcing of millennial- and orbital-scale variability," Marine Geology, vol. 201, no. 1-3, pp. 223-250, 2003.

[28] H. N. Xu, H. Shu, L. Q. Li, M. Zhang, and G. X. Zhang, "3$\mathrm{D}$ seismic data processing techniques for gas hydrate by the single-source and single-cable acquisition method," Progress in Geophysics, vol. 24, no. 5, pp. 1801-1806, 2009 (Chinese).

[29] G. Robinson, "Stochastic seismic inversion applied to reservoir characterization," CSEG Recorder, pp. 36-40, 2001.

[30] N. Satyavani, K. Sain, M. Lall, and B. J. P. Kumar, "Seismic attribute study for gas hydrates in the Andaman Offshore India," Marine Geophysical Researches, vol. 29, no. 3, pp. 167175, 2008.

[31] M. H. Taylor, W. P. Dillon, and I. A. Pecher, "Trapping and migration of methane associated with the gas hydrate stability zone at the Blake Ridge Diapir: new insights from seismic data," Marine Geology, vol. 164, no. 1-2, pp. 79-89, 2000.

[32] M. Ojha and K. Sain, "Seismic attributes for identifying gas-hydrates and free-gas zones: application to the Makran accretionary prism," Episodes, vol. 32, no. 4, pp. 264-270, 2009. 

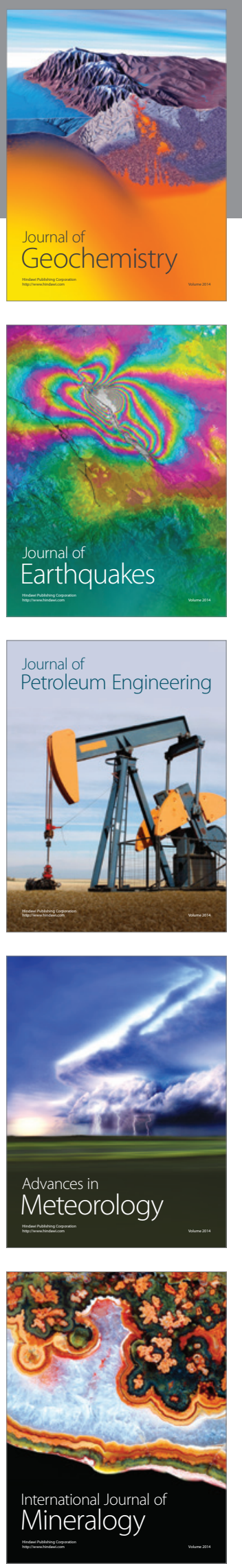
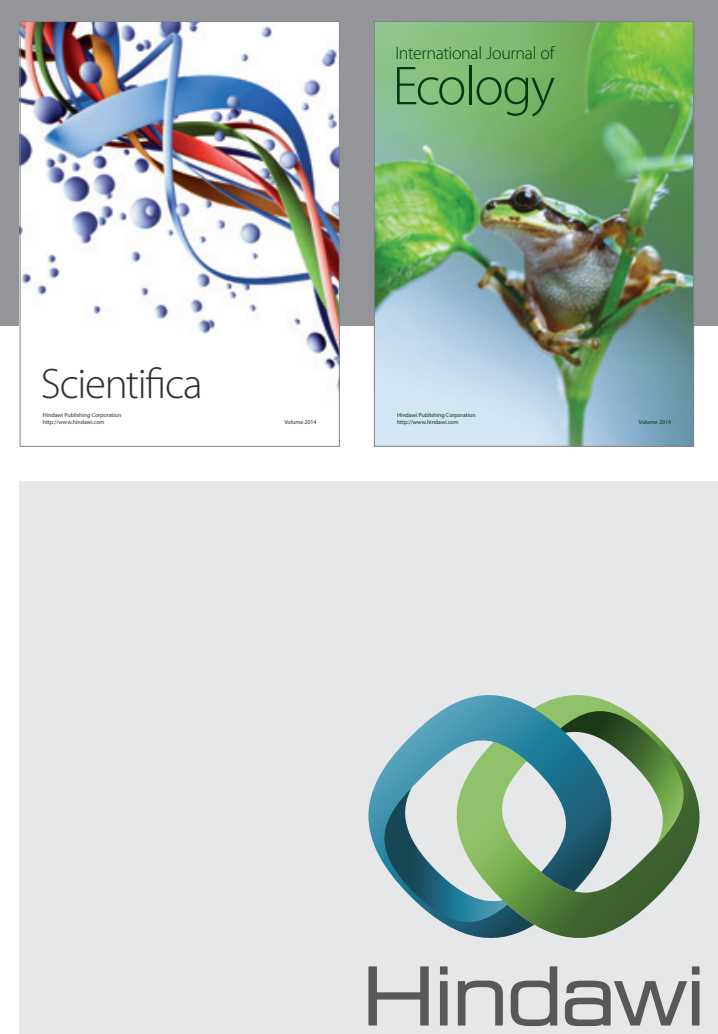

Submit your manuscripts at http://www.hindawi.com
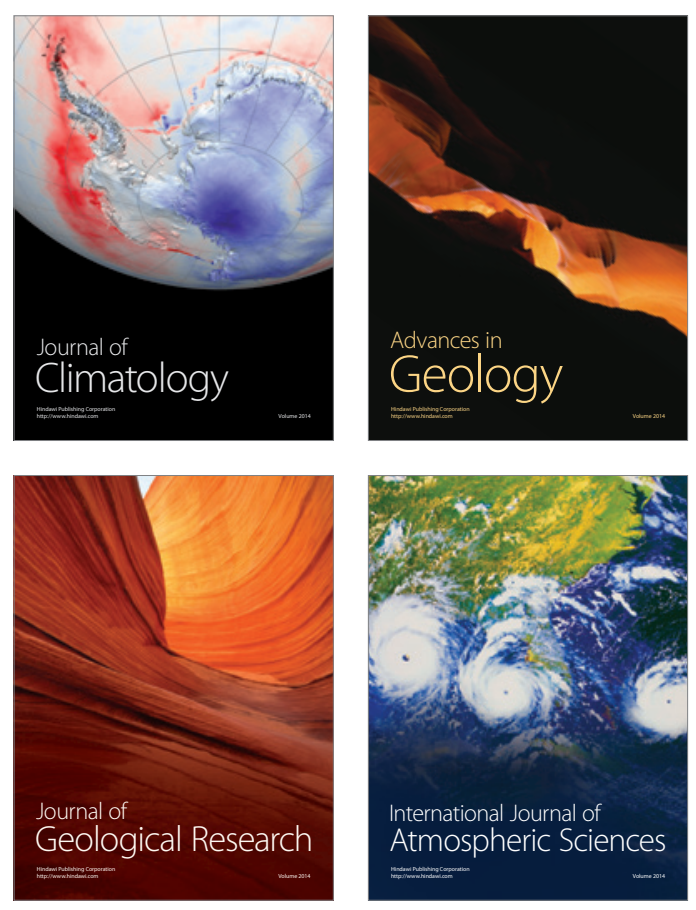
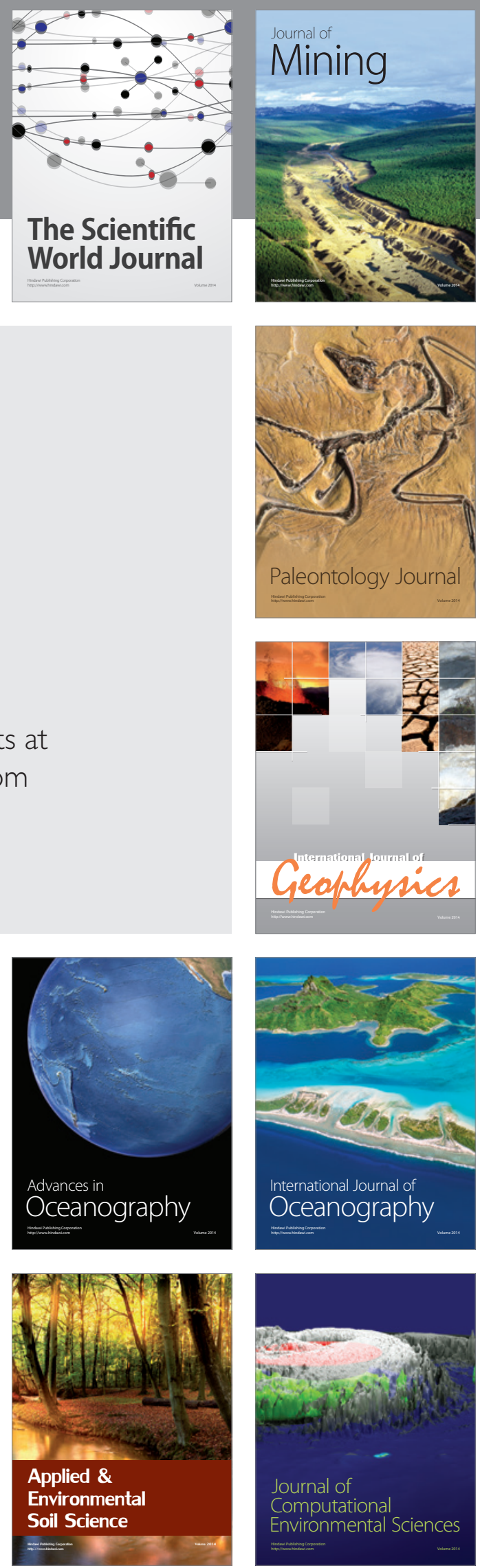